\title{
The creation and pilot validation of the Greek test for auditory discrimination (in minimal pairs) for pre -school children Dionysios Tafiadis*1, Eugenia Chorozopoulou ${ }^{1}$, Eupraxia Tsanousa ${ }^{3}$ and Maria Tafiadi²
}

Address: ${ }^{1}$ Department of Speech Language Therapy, Technological Institute of Ioannina, Ioannina Greece, ${ }^{2}$ Department of Mathematics, University of Patras, Patras, Greece and ${ }^{3}$ Department of primary education, University of Ioannina, Ioannina, Greece

* Corresponding author

from International Society on Brain and Behaviour: 3rd International Congress on Brain and Behaviour

Thessaloniki, Greece. 28 November - 2 December 2007

Published: 17 April 2008

Annals of General Psychiatry 2008, 7(SuppI I):SI 99 doi:10.II86/I744-859X-7-SI-SI 99

This abstract is available from: http://www.annals-general-psychiatry.com/content/7/SI/SI 99

(C) 2008 Tafiadis et al.; licensee BioMed Central Ltd.

\section{Background}

The present research was the creation and pilot validation of the T.A.D. (test of auditory discrimination in minimal pairs) for the Greek population. T.A.D. was created to diagnose the ability of auditory discrimination in pre school children.

\section{Materials and methods}

In this research took part 40 participants (20 boys - 20 girls) recruited from the Greek pre - school population at the region of Thessalonica. The sample was taken in random order; it was independent from origin and socio economic situations, aged from 5years - 0 months till 5 years - 11 months. The test, was administrated to all 40 children, was the T.A.D., which was created from Tafiadis and Chorozopoulou. Also an ENT and a psychological examination were also requested.

\section{Results}

Statistical analysis of the data revealed that, some pairs should be changed. The reasons of those changes were due the wrong choice of pictures or due to the wrong choice of the minimal pair. In our effort to compare our sample due to sex, non-statistical significant differences occurred, for the voiced pairs $(\mathrm{t}=-0,239, \mathrm{df}=19$, NS - sig. 2 - tailed $=0,163)$. And also for the voiceless pairs $(\mathrm{t}=-$ $0,223 \mathrm{df}=19$, NS - sig. 2 - tailed $=0,223$ ). The Reliability of the test also was measured, Coefficients Alpha.1672. The results shown that pairs that have to be changed are [(give
- drink) (dino - pino)], [(tent - dog) (skini - skili), and [(three - cold) (tria - kria)].

\section{Conclusions}

The creation and validation of a new test for the acoustic discrimination in minimal pairs (T.A.D.) its the first step for the diagnosis of specific learning disabilities or language - speech disorders. Trough the analysis, seamed positive that we managed to see that the majority of the participant had the acoustic discrimination ability. The crushing majority of the participants are able to discriminate sounds (both voiced and voiceless). However, there are not statistically differences in accordance to sex, the age of the children the ENT examination and the psychometric evaluation. 